\title{
Research on the Optimization Model of Vehicle Logistics
}

\author{
Xiao $\mathrm{Xie}^{\mathrm{a}}$, Jun Jie He ${ }^{\mathrm{b}}$ and Chuan Da Qi ${ }^{\mathrm{c*}}$ \\ College of mathematics and information science, Xinyang Normal University, Xinyang, China, \\ 464000 \\ a879400325@qq.com, bhejj99@163.com, ’qichuanda@sian.com
}

Keywords: Linear programming; Integer programming; LINGO; Transportation problem; Vehicle logistics

\begin{abstract}
By establishing mathematics model, this paper studies the problem of logistics company's rapid delivery for the whole car according to the customer order. The model according to the loading pattern to arrange transportation is integer linear programming model, which based on considering two types of car carriers all possible loading model, the number of car carrier used to transport in each of the transport loading mode as the decision variables, the minimal total number of car carrier and the lowest total cost as the goal, to establish a multi-objective integer linear programming model.
\end{abstract}

\section{Introduction}

Vehicle logistics refers to the entire process of logistics company rapid delivery for the whole car according to the customer order. According to the customer's purchase order, passenger car manufacturers issue the transportation assignment to the logistics company across the country, then the company makes transportation planning to satisfy the task of transportation and distributes the passenger cars. Therefore, logistics company should first choose some Car carriers from which they can use, and then they give a loading scheme and destination of each passenger car, to ensure the completion of task.

Car carrier is a special carrier vehicle by highway to transport passenger car. Depending on the different model, it can be divided into single layer and double layer. Because the Car carrier of single layer can be seen as the double layer of which the upper length is zero, This article only consider two types of Car carriers with double layer as follows: both the upper layer and the lower layer load one column,named type 1-1, the lower layer and the upper layer respectively load one or two columns, named type 1-2.The specification of Car carrier sees table 1, the specification of passenger car sees table 2 .

Table 1 The specification of Car carrier

\begin{tabular}{|c|c|c|c|}
\hline The type of passenger car & Length(meter) & Width(meter) & Height(meter) \\
\hline I & 4.61 & 1.7 & 1.51 \\
\hline II & 3.615 & 1.605 & 1.394 \\
\hline III & 4.63 & 1.785 & 1.77 \\
\hline
\end{tabular}

Table 2 The specification of passenger car

\begin{tabular}{|c|c|c|c|}
\hline $\begin{array}{c}\text { The type of } \\
\text { Car carrier }\end{array}$ & $\begin{array}{c}\text { The length } \\
\text { (meter) }\end{array}$ & $\begin{array}{c}\text { The width of the upper layer } \\
\text { (meter) }\end{array}$ & $\begin{array}{c}\text { The width of the lower layer } \\
\text { (meter) }\end{array}$ \\
\hline $1-1$ & 19 & 2.7 & 2.7 \\
\hline $1-2$ & 24.3 & 3.5 & 2.7 \\
\hline
\end{tabular}

On the premise of ensure the transportation task accomplished, the logistics company pursues reducing transport costs. Because the Car carrier and passenger car have a variety of specifications, many current logistics companies make transportation planning mainly depend on the dispatcher's 
experience, clearly inefficient in the face of the complex transport tasks, and the transportation cost is far from satisfaction.

The main factors influencing the logistics costs of the whole vehicle are as follows: the amount usage of Car carrier, and the type of passenger car, the lager the loading capacity, the higher the cost, but each time the amount usage of type 1-2 Car carrier should not exceed 20\% of the type 1-1.

According to the given transport demand as follows, we establish optimization model, and then confirm the number of all types of passenger car we need and per vehicle's loading scheme.

i) The logistics company wants to transport 100 passenger cars of type I and 68 passenger cars of type II.

ii) The logistics company wants to transport 72 passenger cars of type II and 52 passenger car of type III.

iii) The logistics company wants to transport 156 passenger cars of type I, 68 passenger cars of type II and 39 passenger cars of type III.

The calculation of transportation cost is relatively complex, here it is simplified, the reasons influences the entire consuming cost are as follows: fist, the use of Car carrier directly, second, when the amount of Car carrier is alike, the usage of type1-1 is lower, the type1-2 slightly higher, while its ownership is small. For the convenience of the subsequent mission requirement, each time the amount usage of type 1-2 Car carrier should not exceed $20 \%$ of the type 1-1. Last, Logistics Company is a national company and has operations around the world. Therefore, the Car carrier arrival in destination on standby, without returning empty, and the unloading cost is almost negligible.

Question 1 only consider the transportation problem of Car carrier of type I and type II. while the question 2 mainly consider the transportation problem of Car carrier of type II and type III. Thus they can be thought as a special case of the question 3. We set up two universal models from different aspects, which can solve the three questions above independently.

The following study we always assume that all columns passenger cars are placed vertically, between adjacent passenger car longitudinal and transverse safety interval at least 0.1 meters, in order to guarantee the stability and safety of car transporter, the lower layer strives to fill, the two columns of the upper layer is symmetrical. Restricted by the height, the passenger cars whose height more than $1.7 \mathrm{~m}$ can only be loaded on the lower layer of the car carrier.

\section{The model based on the loading pattern}

The description of decision variables and parameters. Let $m, n$ respective represent the kind of loading mode of the type 1-1 and type 1-2 Car carrier. $x_{i}, y_{i}$ respective represent the number of the type 1-1 and type 1-2 Car carrier used to transport passenger car in the loading mode ii. $a_{i j}, b_{i j}$ respective represent the number of the j-type passenger car loaded on the the type1-1 and type 1-2 Car carrier in the loading mode i. $C_{1}, C_{2}$ respective represent the transportation cost of the type1-1and type 1-2 Car carrier, and $C_{2}>C_{1} \cdot d_{j}$ represents the number of j-type passenger car that be used to transport in each task.

Target analysis. For each transport tasks, the amount usage of the Car carrier of type1-1and type 1-2 respectively symbolized $\sum_{i=1}^{m} x_{i}$ and $\sum_{i=1}^{n} y_{i}$. so the total cost is $C_{1} \sum_{i=1}^{m} x_{i}+C_{2} \sum_{i=1}^{n} y_{i}$, then set two goals as follows:

i) To minimize the total number of used car transporter, that is

$$
\min Z_{1}=\sum_{i=1}^{m} x_{i}+\sum_{i=1}^{n} y_{i}
$$

ii) To minimize the total cost, that is 


$$
\min Z_{2}=C_{1} \sum_{i=1}^{m} x_{i}+C_{2} \sum_{i=1}^{n} y_{i}
$$

Constraint. Working with constrains. Each time the amount usage of the type 1-2 car transporter should not exceed $20 \%$ of the type $1-1$, that is

$$
\sum_{i=1}^{n} y_{i} \leq 0.2 \sum_{i=1}^{m} x_{i}
$$

Transportation task constraints. Let $d_{j}$ means the number of $\mathrm{j}$-type passenger car that be used to transport in each task, and $\sum_{i=1}^{m} a_{i j} x_{i}, \sum_{i=1}^{n} b_{i j} y_{i}$ respective represent the number of Car carrier of type 1-1 and type 1-2 which are used to transport the j-type passenger car,that is

$$
\sum_{i=1}^{m} a_{i j} x_{i}+\sum_{i=1}^{n} b_{i j} y_{i} \geq d_{j}, j=1,2,3
$$

Integer constraints. The number of vehicle are positive integer, that is

$$
\left\{\begin{array}{l}
x_{i} \geq 0, \text { and } x_{i} \in Z, i=1,2, \cdots, m, \\
y_{i} \geq 0, \text { and } y_{i} \in Z, i=1,2, \cdots, n .
\end{array}\right.
$$

Linear programming model is established. Based on the above analysis, with the form of (1),(2) as the goal, (3), (4), (5) as the constraint conditions, that is

$$
\begin{aligned}
& \min Z_{1}=\sum_{i=1}^{m} x_{i}+\sum_{i=1}^{n} y_{i}, \\
& \min Z_{2}=C_{1} \sum_{i=1}^{m} x_{i}+C_{2} \sum_{i=1}^{n} y_{i} \\
& \text { s.t. }\left\{\begin{array}{l}
\sum_{i=1}^{n} y_{i} \leq 0.2 \sum_{i=1}^{m} x_{i}, \\
\sum_{i=1}^{m} a_{i j} x_{i}+\sum_{i=1}^{n} b_{i j} y_{i} \geq d_{j}, j=1,2,3 \\
x_{i} \geq 0, \text { and } x_{i} \in Z, i=1,2, \cdots, m, \\
y_{i} \geq 0, \text { and } y_{i} \in Z, i=1,2, \cdots, n .
\end{array}\right.
\end{aligned}
$$

The solution of programming model. Solutions to the question 1 and 2: Through the enumeration can be summed up that the Car carrier of type 1-1and type 1-2 respectively has 9 and 16 kinds of loading mode. These loading models can be expressed in matrix form :

$$
\begin{aligned}
& A=\left(a_{i j}\right)=\left(\begin{array}{lllllllll}
8 & 7 & 6 & 5 & 4 & 3 & 2 & 1 & 0 \\
0 & 1 & 2 & 3 & 5 & 6 & 6 & 8 & 10
\end{array}\right)^{\prime}, \\
& B=\left(b_{i j}\right)=\left(\begin{array}{cccccccccccccccc}
15 & 14 & 13 & 12 & 11 & 10 & 9 & 8 & 7 & 6 & 5 & 4 & 3 & 2 & 1 & 0 \\
0 & 1 & 2 & 4 & 5 & 6 & 8 & 9 & 10 & 12 & 13 & 14 & 15 & 16 & 17 & 18
\end{array}\right)^{\prime},
\end{aligned}
$$

Where $a_{i j}\left(b_{i j}\right)$ means the each Car carrier of type 1-1(1-2) can load the quantity of the j-type passenger car in the loading mode $\mathrm{i}$.

Since the cost of Car carrier of type 1-1 is lower, type 2-2 is higher, type 1-2 is slightly lower than the averages, let $C_{1}=1, C_{2}=1.2$. The result is calculated by Lingo software programming is as follows: 16 Car carriers of type 1-1are needed, in which the 10 passenger cars according to the mode1, 6 passenger cars according to the mode 9,2 Car carriers of type 1-2are needed, in which one passenger car according to the mode 1 and one according to the mode 10. 
Actually, the transport capacity of 18 Car carriers is beyond the amount of passenger cars to transport. Trimming the extra vehicles, in the 10th mode, the upper layer of Car carrier of type 1-2 need to reduce one passenger car of type I and 4 passenger cars of type II .

Similarly, the result of question 2 is that 12 Car carriers of type 1-1 demanded as the 5 th mode and only one Car carrier of type1-2 demanded as the 6th mode .

Solution of question 3. We can draw a conclusion that:when Car carrier transport the three types of passenger cars, the 1-1 type of Car carrier has 35 kinds of loading modes, and the 1-2 type has 81 kinds of loading modes. plug the above data, the result is calculated by Lingo software programming to see table 3 .

Table 3 The result is calculated by Lingo software programming

\begin{tabular}{|c|c|c|c|c|c|c|c|}
\hline \multirow{2}{*}{$\begin{array}{c}\text { The type } \\
\text { of Car } \\
\text { carrier }\end{array}$} & $\begin{array}{c}\text { Loading } \\
\text { mode }\end{array}$ & $\begin{array}{c}\text { The } \\
\text { number of } \\
\text { Car carrier }\end{array}$ & $\begin{array}{c}\text { The number } \\
\text { of passenger } \\
\text { car I }\end{array}$ & $\begin{array}{c}\text { The number } \\
\text { of passenger } \\
\text { car II }\end{array}$ & $\begin{array}{c}\text { The number } \\
\text { of passenger } \\
\text { car I }\end{array}$ & $\begin{array}{c}\text { The number } \\
\text { of passenger } \\
\text { car II }\end{array}$ & $\begin{array}{c}\text { The number } \\
\text { of passenger } \\
\text { car III }\end{array}$ \\
\hline \multirow{5}{*}{ Type 1-1 } & 9 & 12 & 4 & 0 & 4 & 0 & 0 \\
\cline { 2 - 8 } & 19 & 1 & 1 & 4 & 0 & 2 & 2 \\
\cline { 2 - 8 } & 26 & 7 & 0 & 5 & 1 & 0 & 3 \\
\cline { 2 - 8 } & 34 & 1 & 3 & 1 & 0 & 0 & 4 \\
\hline Type 1-2 & 10 & 5 & 4 & 0 & 0 & 0 & 4 \\
\hline
\end{tabular}

\section{Conclusions}

As the problems 1-3 in this paper, it involves three types of passenger car's transportation problem. To build optimization mode, we should take the carrier loading capacity of the car carrier, the use ratio, the transport task, the type of III passenger car only can be loaded on the substratum as the constraint conditions, the least use of the total number of passenger cars and the lowest of the total cost as the goal.

\section{References}

[1] J.Y.Xu. Applied Study on Establishing The Shipping Model and Optimal Algorithm of Vehicle Logistics[D]. Shanghai Jiao Tong University,2012.

[2] T.S.Zhang. The Vehicle Logistics Distribution Path Optimization Research of SQ[D]. Dalian Maritime University,2012.

[3] X.W.Qin,Y.S.Fan,C.W.Yin.The Research on Integration and Optimization of Network Planning of Vehicle Logistics ( [J]. Computer Integrated Manufacturing System,2006,03:364-370+376.

[4] S.H.Ma,X.L.Zhang. Logistics Capacity Constraints Based on Vehicle Logistics Plan [J]. IE\&M,2006,06:15-18+32.

[5] W.Yang,T.Li,Z.Li.The Research Integration of Vehicle Logistics and Its Solution [J].logistics management,2005, 10:46-48.

[6] S.P.Gao.The Fuzzy Optimization Algorithms and Theory of Transportation Problem[D].Xidian University,2003.

[7] D.Y.Liu. Study on Transportation Problem with Capacity Limitation [D]. Beijing Jiaotong University,2009.

[8] P.Jin, R.C.Zuo. S. L.Yang,H.W.Ma. The cutting stock problem and transportation problem[J]. Chinese Journal of Management Science,2013,02:91-97 
[9] J.Zhang.J.F.Tang,Z.D.Pang. Simulation Study on The Integrated Inventory Transportation Problem of Different Transportation Modes[J]. Journal of Northwestern University (Natural Science Edition),2008,04:492-495.

[10] Z.G.Han. Mathematical Modeling Method and Its Application-( The Second Edition)[M], Higher Education Press,2009. 